\section{Cation Analysis of Woods Hole Sea Water}

Tre Marine Biological Laboratory at Woods Hole, Massachusetts, provides running sea water from tanks which are supplied by a pumping system from a point where currents and depth ensure purity. This water provides media for many biological experiments and its cationic constitution may be of significance. Water drawn from this system has been analysed for sodium, potassium, calcium and magnesium.

Sodium and potassium analysis. These ions were determined by comparison against known concentrations in the Toner-Pitts flame photometer. This sensitive instrument balances a specific lithium ion concentration against the sodium or potassium ion, and the result is found photometrically through specific filters. Either ion may be determined in the presence of the other. - Sodium was found to have a value of 534 millimols per litre; and potassium was found to have a value of $18 \cdot 2$ millimols per litre.

Calcium analysis. The calcium was precipitated with an excess of ammonium oxalate, washed, filtered, and this calcium oxalate was dissolved in 1 : 20 sulphuric acid and then titrated to faint pink as end point with $0.01 \mathrm{~N}$ potassium permanganate, according to the equation :

$5 \mathrm{CaC}_{2} \mathrm{O}_{4}+2 \mathrm{KMnO}_{4}+8 \mathrm{H}_{2} \mathrm{SO}_{4}=$

$5 \mathrm{CaSO}_{4}+\mathrm{K}_{2} \mathrm{SO}_{4}+2 \mathrm{MnSO}_{4}+10 \mathrm{CO}_{2}+8 \mathrm{H}_{2} \mathrm{O}$

from which there is a calcium/permanganate ratio of $2.5: 1$; this yields a calcium concentration of $5 \cdot 8$ millimols per litre.

Magnesium analysis. The magnesium was precipitated with dibasic sodium phosphate in the presence of excess ammonium hydroxide to form magnesium ammonium phosphate, and the completeness of precipitation was checked by aliquot addition of more sodium phosphate reagent, a volumetric adaptation of the standard gravimetric technique. The phosphate and magnesium have a direct ratio and the end point found yields a magnesium concentration of $56 \cdot 2$ millimols per litre.

\begin{tabular}{lr}
\multicolumn{2}{c}{ MHLIMOLS PRR LitRe FoUND } \\
Sodium & $\mathbf{5 3 4 \cdot 0}$ \\
Potassium & $18 \cdot 2$ \\
Magnesium & $56 \cdot 2$ \\
Calcium & $5 \cdot 8$
\end{tabular}

Dry weight of salts. Taking into account the ratios of sulphates, chlorides and bromides (Lyman and Fleming ${ }^{1}$, conversion of the above values into grams per litre yielded $39.32 \mathrm{gm}$. per litre, which is found to compare favourably with a value of $39 \cdot 36$ as directly measured from a three-litre sample of water.

Discussion. As will be found by reference to Lyman and Fleming ${ }^{1}$, as well as to Thompson and Robinson ${ }^{2}$, sodium values hitherto have been by differences after the other ions have been determined. Potassium values are open to the criticism that gravimetric analysis yields a loss factor that is not constant. The constancy of various ion ratios to the chlorinity is not upheld by photometric analysis for potassium, neither is it for the calcium value. Of more significance to this work is that of Page ${ }^{3}$, the last recorded analysis of this material, in which there was found by gravimetric means a value of 382.6 millimols of sodium, and a dry weight computable from this of $28 \cdot 8 \mathrm{gm}$. per litre. There is good correlation in the percentages of dry weight for magnesium with Page's value $\mathbf{3 \cdot 4}$, and this work giving $3 \cdot 5$. There is not good correlation on the calcium values, Page's being 1.2 per cent by weight, and the present work giving just half of that.

Other physical data that may be derived from this analysis are the specific gravity and the chlorinity. When computed on Dittmar's original formula 4 , this former is found to be $1 \cdot 0303$, and when computed on the formula offered by Thompson and Robinson ${ }^{2}$ the specific gravity is $\mathbf{1} \cdot 0293$. The chlorinity is computed to be 22.06 parts per thousand. The molal lowering is measured at $2.07^{\circ} \mathrm{C}$, and computed from Thompson and Robinson to be $2.08^{\circ} \mathrm{C}$. These fail to agree with the table for water of this chlorinity in the data of Dittmar, which gives the value of $2 \cdot 18^{\circ} \mathrm{C}$. and a value of $41 \cdot 2 \mathrm{gm}$. dry salts per litre. It should be noted that Dittmar's values are for deep-sea surface and depth waters, and the present analysis is for a specific coastal subsurface water.

D. R. SHANKLIN

New York State College of Medicine at Syracuse, and Marine Biological Laboratory, Woods Hole,

Massachusetts. Sept. 14.

${ }^{1}$ Lyman, J., and Fleming, R. H., J. Mar. Res., 3, 134 (1940). ${ }^{2}$ Thompson, T. G., and Robinson, R. J., Bull. Nat. Res. Coun., 85, 95 (1932).

${ }^{3}$ Page, I. H., Biol. Bull., 52, 161 (1927); 55, 449 (1928).

"Dittmar, W., "Voyage of the Challenger", Chemistry and Physics, Vols. 1 and 2 (1884)

\section{Experimentally produced 'Polyagglutin- ability' (T-Transformation of Erythrocytes in vivo) in Guinea Pigs infected with Pneumococci}

IT has been known for many years that treatment of erythrocyte suspensions with certain bacterial culture filtrates (for example, cholera vibrio) alters the erythrocytes so that they become agglutinable by practically all human sera. This phenomenon of 'panagglutinability' has been thoroughly discussed by Friedenreich". It appears to be due to enzymic action on the cell surface, whereby a new antigen or receptor (designated $T$ ) is revealed, which reacts with a corresponding, very widespread antibody ( $T$ antibody). Chu ${ }^{2}$ showed that certain pathogenic bacteria, including all types of pneumococcus, could bring about this change. Occasional patients are encountered whose erythrocytes show a phenomenon of polyagglutinability, which appears to be closely related to the appearance of $T$-antigen. It was therefore of interest to try to produce this state experimentally in animals by means of infection with bacteria that are known to transform erythrocytes in vitro.

Guinea pigs have been used for the experiments, as Friedenreich ${ }^{1}$, on examination of the erythrocytes of various species, has found those of the guinea pig greatly to resemble human erythrocytes with regard to the $T$-transformation. As pneumococcus Type 19 naturally is pathogenic to guinea pig $^{3}$ and capable of $T$-transformation of guinea pig erythrocytes in vitro, this type of pneumococcus was chosen for the investigation.

In the first experiment, six guinea pigs uniform in weight, colour and age were used. Cultures from the nose, which often harbours pneumococci, proved the nasal cavity in these guinea pigs to be free from 